\title{
A OUTRA FACE DE FIGUEIREDO PIMENTEL: PRODUÇÕES LÍRICAS, DRAMÁTICAS E NOS FOLHETINS
}

\section{THE OTHER FACE OF FIGUEIREDO PIMENTEL: LIRIC, DRAMATIC AND SERIALIZED SENSATION PRODUCTIONS}

\section{Cristina Rothier Duarte* $U F P B$}

\section{Daniela Maria Segabinazi** $U F P B$}

Resumo: Figueiredo Pimentel, considerado o precursor cronológico da literatura infantil brasileira, ao publicar em 1894, Contos da Carochinha, pela Livraria Quaresma, foi um escritor bastante atuante em variados gêneros literários, contudo os estudos se limitam a tratar da produção infantil ou de suas narrativas naturalistas, de modo que seus trabalhos líricos e dramáticos permanecem desconhecidos na história da literatura brasileira. Diante desse contexto, temos como objetivo tratar, além de poemas e textos dramáticos do autor, de algumas narrativas de sua autoria que circularam em periódicos fluminenses, nos anos finais do século XIX, no formato de folhetins. Para tanto realizamos consulta junto à Hemeroteca Digital da Biblioteca Nacional, e utilizamos como referencial teórico Mendes (2015; 2016), Mendes e Leite (2015), Vieira (2015), entre outros. Os resultados nos levaram a perceber que a produção de Figueiredo Pimentel, embora bastante extensa, é pouco estudada e reconhecida, necessitando de uma maior atenção dos pesquisadores que investigam a história da literatura brasileira.

Palavras-chave: História da literatura. Literatura brasileira do século XIX. Figueiredo Pimentel.

\begin{abstract}
Figueiredo Pimentel, considered the chronological precursor of Brazilian children's literature, published in 1894, Contos da Carochinha by Livraria Quaresma, was a very active writer in various literary genres, however, studies are limited to dealing with children's production or their naturalistic narratives, so that his lyrical and dramatic works remain unknown in the history of Brazilian literature. In this context, we aim to treat, in addition to poems and dramatic texts of the author, some narratives of his authors that circulated in Rio de Janeiro periodicals, in the late nineteenth century, in the format of serials, to the Hemeroteca Digital da Biblioteca Nacional, and we use as theoretical reference Mendes (2015, 2016), Mendes and Leite (2015), Vieira (2015), and others. The results lead us to notice that Figueiredo Pimentel 's production, although quite extensive, is little studied
\end{abstract}

\author{
${ }^{*}$ Especialista \\ em Ciências da \\ Linguagem com \\ Ênfase no Ensino da \\ Língua Portuguesa \\ (CLELP) - UFPB; \\ Mestranda pelo \\ Programa de Pós- \\ Graduação em Letras \\ da UFPB. E-mail: \\ cristinarothier@ \\ hotmail.com. \\ ** Professora Doutora \\ do Departamento de \\ Letras e do Programa \\ de Pós-Graduação \\ em Letras da \\ Universidade Federal \\ da Paraíba. E-mail: \\ dani.segabinazi@ \\ gmail.com.
}


and recognized, requiring a greater attention of researchers that investigate the history of Brazilian literature.

Keywords: History of literature. Brazilian literature of the nineteenth century. Figueiredo Pimentel.

\section{Introdução}

Nascido em 11 de outubro de 1869, em Macaé, interior do Rio de Janeiro, então Capital Federal brasileira, Figueiredo Pimentel foi um escritor muito ativo, destacando-se devido à sua abundante produção como jornalista e escritor nos anos finais dos oitocentos e início dos novecentos. Considerado por Renata Ferreira Vieira (2015, p. 10) um polígrafo, “[...] produziu uma extensa quantidade de obras, em variados gêneros textuais: conto, poesia, crônica, teatro, folhetim, romance e literatura infantil, desempenhando várias facetas literárias em sua trajetória.”

No jornalismo, ramo em que começou sua carreira profissional, atuou, concomitantemente, como colaborador nos jornais fluminenses Gazeta de Notícia e A Notícia, ${ }^{1}$ assim como Olavo Bilac (1865-1918) e João do Rio (1881-1921). Porém, também escreveu para outros tantos periódicos, como: Província do Rio, em que circulou $O$ artigo 200; O Paiz; Arcádia: revista d'arte etc., como veremos mais adiante.

No âmbito literário livresco, Figueiredo Pimentel foi uma figura bastante polêmica cuja escrita naturalista, à época, foi severamente tachada de pornográfica, inclusive tendo o folhetim $O$ artigo 200 censurado pelo público leitor, o que o obrigou a trazer antecipadamente um desfecho para a narrativa, de modo que o próprio escritor o considerou forçado e destoante do estilo literário que havia traçado.

Além de escritor de folhetins e romances, trabalhou como cronista, ditando moda e comportamentos parisienses no Rio de Janeiro, na coluna “Binóculo”, do jornal Gazeta de Notícias, bem como foi correspondente em periódicos franceses.

Vemos, portanto, sua atuação em meio a gêneros jornalísticos e literários, mas ele não parou por aí, pois, ainda como escritor, buscou outro público, dedicando-se também à produção para crianças. Nesse ramo, alcançou sucesso absoluto, em seu tempo, com as publicações da coleção Biblioteca Infantil, da Livraria Quaresma, prova disso é que as obras esgotavam-se pouco tempo depois de postas à venda.

Como podemos perceber, Figueiredo Pimentel era um escritor imensamente produtivo, que não se acomodava em um gênero literário, nem se dedicava a apenas uma atividade profissional, todavia é pouco estudado, ou são escassas as pesquisas que o tomam como objeto de estudo, e, quando existentes, abordam sua escrita naturalista ou sua produção infantil editada

\footnotetext{
${ }^{1}$ Maria Alice Rezende de Carvalho (2012, p. 63) explica que "[a]lguns historiadores da imprensa brasileira afirmam tratar-se de uma só empresa. Mas as atas de suas respectivas assembleias indicam serem duas organizações distintas, [...].”.
} 
pela Livraria Quaresma. Como escritor de folhetim e dos gêneros lírico e dramático, não temos notícias de trabalhos que tenham se dedicado ao assunto, de modo que, neste artigo, propomos uma investigação de cunho histórico, realizada a partir da recolha de informações, nos arquivos da Hemeroteca Digital da Biblioteca Nacional, sobre esse autor, com o intuito de trazer contribuições válidas para a historiografia da literatura nacional no que diz respeito à sua produção literária e à crítica da época.

\section{Figueiredo Pimentel nos periódicos}

Figueiredo Pimentel começou sua vida profissional no jornalismo carioca ainda bastante jovem. Segundo Vieira (2015, p. 15), no jornal Província do Rio, na década de 90 do século XIX, o escritor macaense assumiu alguns pseudônimos, por meio dos quais publicou vários textos: Albino Peixoto, autor do folhetim O artigo 200; Chico Botija, escritor da seção "Entre as X e as XI”, ${ }^{2}$ Abelhudo, como articulista dos artigos de "Para as moças"; Tesoura, autor na seção “Chá de garfo”, e Heitor Vasco, nas colunas sobre poesias.

Após deixar o Província do Rio, foi para O Paiz, em 1891, onde trabalhou como jornalista e editor. Sua intensa atividade no jornalismo somada à sua participação na vida literária local tornou-o bastante conhecido da sociedade carioca, de modo que “[...] era quase impossível não se falar dele, pois parecia estar em todos os lugares ao mesmo tempo. [...] Estava presente nas conferências literárias mais badaladas, nas redações dos principais jornais, nos aniversários e enterros de escritores, quando proferia discursos.” (MENDES; LEITE, 2015, p. 118-119).

Nesse sentido, Vieira (2015, p. 15) relata que

[a]pós sua passagem pelo Província do Rio, Figueiredo Pimentel prosseguiu na carreira de escritor e jornalista em diversos jornais da capital federal. Na década de 1890, a profusão de seus trabalhos literários ganhou repercussão na opinião pública. Em 1891, no cargo de redator de O País, ao lado do colega de trabalho, o escritor e jornalista maranhense Coelho Neto, Figueiredo Pimentel ampliou suas relações sociais entre os homens de letras e efetuou negócios promissores num mercado editorial em expansão [...].

De acordo com Leonardo Mendes (2015), ao apresentar a primeira edição de $O$ aborto, pela editora 7 Letras, Figueiredo Pimentel, sob o pseudônimo de Albino Peixoto, publicou, em 1889, O artigo 200, em folhetim, no Província do Rio:

Fazendo referência ao artigo do Código Penal do Império que criminalizava o aborto, a obra contava a história de Maricota, uma jovem de dezessete anos de modestas posses, natural de Rio Bonito (RJ) e moradora do bairro de Icaraí, em Niterói. Maricota era uma moça avançada entre seu grupo de amigas, lia romances naturalistas franceses e sentia-se confortável com o

\footnotetext{
${ }^{2}$ Em nossas consultas junto à Hemeroteca Digital da Biblioteca Nacional, encontramos a coluna "Entre as X e as XI", de Chico Botija, em O Fluminense (1892).
} 
próprio corpo e com a sexualidade. Ao final ela engravidava e morria ao tentar um aborto com a ajuda do primo, que era farmacêutico e pai da criança.

[...]

O folhetim causou tanto escândalo que o Província do Rio se viu obrigado a interromper a publicação antes do final da história. [...] (MENDES, 2015, p. 10).

Tal fato, entretanto, não frustrou a sua trajetória como escritor - pois, após quatro anos, com os folhetins de $O$ artigo 200 transformados em livro, publicou $O$ aborto, seu romance de estreia -, bem como não prejudicou sua carreira no jornalismo. Segundo Mendes (2015), além do Província do Rio, Figueiredo Pimentel foi assíduo como colaborador de diversos periódicos, dentre eles: Arcádia, Vera Cruz, Revista do Brasil, Brasil Moderno e Revista Contemporânea, mas seu trabalho não se limitou ao Brasil. Na França, foi correspondente nas revistas Je sais tout e Mercure de France, e no jornal Excelsior, de Paris. Nos jornais cariocas, além de ter trabalhado, conforme já apresentamos, em O Paiz, também escreveu para O Diário de Notícias, Cidade do Rio, Correio da Tarde, O Século e Folha da Tarde, A Notícia, em que assinava a coluna "Pequenos Ecos", que versava sobre as novidades artísticas do Rio de Janeiro.

Ainda em periódico, Figueiredo Pimentel, assinando como Albino Peixoto, publicou, em folhetim, O clube da morte, no jornal Cidade do Rio. A narrativa foi anunciada, em 12 de agosto de 1895, no referido jornal nos seguintes termos: "O Club da Morte é um romance a PONSON DU TERRAIL cheio de enredo, cheio de mortes, crimes, duelos, assassinatos, fuzilamentos, etc., no gênero apreciado pelo publico.”3 (CIDADE DO RIO, ANO 10, n. 184, 12 de ago. 1895, p. 1). Como vemos, já se antecipava que a escrita de Figueiredo Pimentel permaneceria dotada dos apelos polêmicos, a qual contava com destinatários fiéis. Assim, em 15 de agosto do mesmo ano, foi lançado o primeiro capítulo, “Os embuçados”, 4 (FIGURA 1) dando início a uma narrativa contada em 16 (dezesseis) capítulos publicados diariamente.

Figura 1: Capítulo I, de O Club da Morte, de Figueiredo Pimentel (1895)

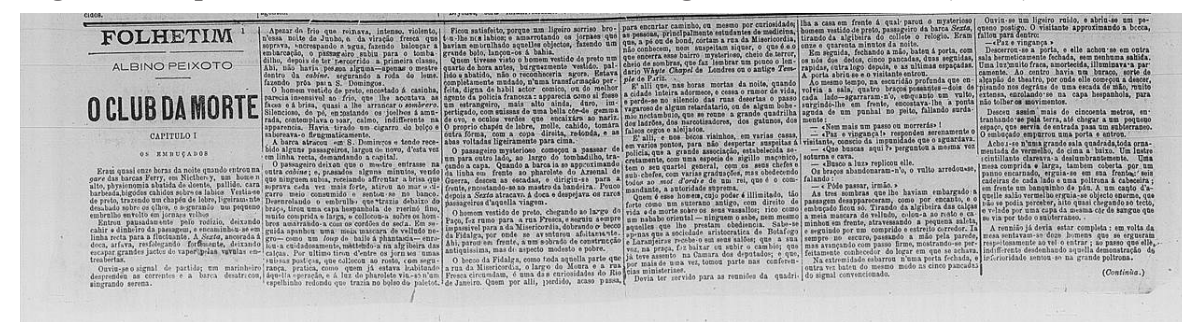

Fonte: Hemeroteca da digital Biblioteca Nacional.

Com sua escrita sem autocensura, Figueiredo Pimentel provocava sentimentos variados na crítica. Ora amado, ora odiado, seu nome sempre aparecia, de alguma forma, nos periódicos de seu tempo. Por exemplo, na
${ }^{3}$ Optamos por manter, nas citações de periódico e produções literárias, a ortografia de acordo com o original.

${ }^{4}$ Publicado no Cidade do Rio, ANO 10, n. 187, em 15 de agosto de 1895. 
“Secção livre”, de O Fluminense, assinada por Moysés, há a expressão de verdadeira admiração pelo escritor:

Agora permitam-me que rapidamente cite alguns moços que são a nossa glória, o nosso orgulho.

Alberto Pimentel de sobre conheço, é o Chico Botija, é o literato distincto, é um typo desinquieto, espantado e tormento dos amigos.

Não sei explicar mesmo o que é o Alberto, sei que elle hoje está como redactor d'O Paiz.

É literato distincto, desinquieto e espantado, porque tem muito talento e é excessivamente nervoso.

É o tormento dos amigos porque onde sempre com os bolços cheios de papeis onde fulgura os centellinhos da sua imaginação... papeis estes que lê de fio a pavio ao pobre diabo que cae lhe nas unhas. [...] (O FLUMINENSE, ANO XIV, n. 2039, 27 mai. 1892, p. 2).

Por outro lado, também em O Fluminense, na seção “Inedictoriaes”, assinada por Manoel Benicio (18-- -19--?), Figueiredo Pimentel foi criticado em razão da simulação de suicídio, a fim de promover seu romance O suicida (1895): “Quanto a mim declaro, senhor redactor, que me chocando com a noticia do fingido suicídio por julgar a victima merecedora de piedade, revoltei-me ao saber que elle fora a enscenação de um reclame espectaculoso e improprio de homens de espirito, talento e bom senso.” (O FLUMINENSE, ANO XVIII, n. 2725, 02 mai.1895, p. 3).

Outro folhetim de Figueiredo Pimentel, publicado em periódicos, foi $O$ cadaver. De acordo com uma nota que circulou no jornal fluminense $A$ Noticia, a narrativa era assinada por Fernão Pinto, pseudônimo usado pelo romancista macaense:

Mais um excelente supplemento ilustrado dá amanhã a Gazeta de Noticias. Entre as muitas coisas interessantes, além de numerosas gravuras de palpitante actualidade, a Gazeta enceta amanhã a publicação da apavorante novella $O$ Cadaver, historia da meia noite, contada por Fernão Pinto, pseudonymo que mal esconde o aplaudido autor do Livro Mau e do Aborto. Além disso, publica ainda o suplemento de amanhã: [...] "Maos costumes", chronica de Figueiredo Pimentel [...]. (A NOTICIA, ANO XVIII, n. 42, 18-18 jan. 1911, p. 1).

Ainda na primeira década dos novecentos, Figueiredo Pimentel, sob o pseudônimo de Petrônio Carioca, assinava o “Binóculo”, do jornal Gazeta de Notícias, do Rio de Janeiro, considerado, conforme Mendes (2015), o mais literário dos periódicos da época. Nessa coluna, “[...] o escritor capitalizou, com grande êxito, sobre as ideias de civilização e modernização desencadeadas pelas reformas urbanas do prefeito Pereira Passos.” (MENDES, 2015, p. 10-11). 
A coluna, segundo Góes (2015, p. 24), era estruturada em fragmentos diversos, mas, dependendo da importância do tema, assumia contornos de crônica: "[u]m recurso usado com regularidade para ambientar o leitor no dia enfocado era iniciar o texto com a descrição do tempo (cronos).”. "Binóculo” circulava aos domingos, ${ }^{5}$ abordando assuntos da sociedade e atualizando seus leitores sobre os últimos acontecimentos. Ainda nessa coluna, tratava de literatura, e, além disso,

[s]e dedicava excepcionalmente a aconselhar pessoas a seguir determinadas regras de comportamento e moda, ou seja, o que usar, onde usar, como usar, principalmente como agir em lugares públicos, em especial, nos ambientes da Avenida Central. A coluna fez tanto sucesso que os jornais adotaram em suas folhas sessões semelhantes, viviam a observar os comportamentos das pessoas e determinar regras de etiqueta na alta sociedade, como padrão a qualquer cidadão. (NUNES, 2009, p. 67).

Figueiredo Pimentel apresentava, assim, uma nova faceta, a de colunista social - “[...] tornou-se, a partir de 1907, o ‘oráculo da beleza’: ditava moda, fazia advertências, ministrava curso de como usar luvas... Todo carioca distinto, elegante e bem informado lia “Binóculo” (DIDIER, 2005 apud SANTOS, 2013, p. 135). Tal era a influência que o escritor exercia sobre a opinião da sociedade carioca, que um hábito tipicamente inglês passou a ser adotado no Rio de Janeiro, conforme reportagem “O chá, no Rio, está na sua edade de ouro...”, divulgada na seção "Os novos hábitos cariocas”, de A notícia. A matéria é iniciada lembrando que o costume carioca era de se tomar café às 22 horas, porém “[a] raça inglesa enviou-nos o five o’clock tea, o saudoso Figueiredo Pimentel adoptou-o, ordenou pelo Binoculo, e a hora do chá passou a ser a hora quinta da tarde, para falarmos evangelicamente, tratando-se do evangelho da elegância.” (A NOTICIA, ANO XXI, n. 156, 3-4 jul. 1914, p. 1).

Apesar de ter ganhado destaque na sociedade carioca, inclusive, influenciando comportamentos, nem sempre fora considerado tão elegante. As obras naturalistas de sua autoria, muitas vezes, provocavam reações negativas, pelo fato de terem sido consideradas como pornográficas. Para o livreiro Pedro Quaresma, no entanto, a imagem polêmica de Figueiredo Pimentel era considerada como um fator positivo capaz de atrair leitores de suas publicações:

A má fama pregressa do escritor e a possibilidade de comercializar obras naturalistas na faixa do livro popular e pornográfico eram incentivos para se arriscar na empreitada. A partir de janeiro de 1893, o livreiro começou a anunciar em notas nos jornais da cidade o lançamento do "empolgante romance naturalista” de Figueiredo Pimentel. (MENDES, 2016, p. 183).

Registradas algumas aparições nos periódicos, seja como escritor, seja como objeto de crítica, passemos à sua produção no gênero lírico e dramáticos.

\author{
${ }^{5}$ Sobre a \\ periodicidade da \\ coluna, Carvalho \\ (2012) informa ser \\ diária. No mesmo \\ sentido, Souza \\ (2002).
}




\section{A produção lírica e dramática de Figueiredo Pimentel}

Como já apresentamos anteriormente, Figueiredo Pimentel foi um autor operoso, que transitava entre suportes e gêneros literários de forma incansável. Mal acabava de lançar uma obra, era anunciada outra, ao mesmo tempo em que não cessava com a produção de seus trabalhos, em periódicos, como jornalista e colunista, afora a sua atuação como editor e escritor. Quanto aos gêneros literários, como já expusemos, foi mais conhecido como autor de obras naturalistas e das obras da Biblioteca Infantil da Livraria Quaresma, como Contos da Carochinha, Contos da Baratinha, Contos da Avozinha entre outros. No entanto, a sua produção lírica e dramática é totalmente desconhecida. Assim, em razão da ausência de estudos acadêmicos, para este trabalho, utilizamos críticas e notas jornalísticas de periódicos predominantemente fluminenses, arquivadas no site da Hemeroteca Digital da Biblioteca Nacional, as quais circularam entre a última década do século XIX e o início do século XX.

A primeira obra de poemas escrita por Figueiredo Pimentel de que tivemos notícia foi Fototipias (1893?). Assim, como em sua prosa naturalista, seus poemas também foram objeto de críticas nos periódicos então coetâneos, por exemplo, em 21 de abril de 1894, A semana, do Rio de Janeiro, publicou uma crítica em que Araripe Júnior classificava Fototipias, ao lado de Evangelhos, de Raymundo Corrêa, como "muito longe de representar aquella impassibilidade poetica e nitidez de forma que os mestres recomendam, e de que no presente são os 'Tropheus' de José Maria de Heredia o mais perfeito exemplo.” (A SEMANA, ANO V, n. 38, 21 abr. 1894, p. 298).

Na mesma crítica, mais à frente, Araripe Júnior acusa Figueiredo Pimentel como acometido da grave moléstia de “japonisar tudo”, o que significa, nas palavras do crítico, uma habilidade para adaptar superficialmente tudo o que se deseja, uma "[h]abilidade de fingir, pondéra o ilustre viajante, mas a que difficilmente corresponde um estado de consciência irreductível.” (A SEMANA, ANO V, n. 38, 21 abr. 1894, p. 299).

Muito embora tais imputações confiram impressões negativas à estética de Figueiredo Pimentel, o crítico reconhece as suas qualidades, ao afirmar que se trata de um escritor de talento, mas “[...] que necessita de ser acossado com ferro em braza, como se costuma fazer ás feras indomaveis. Justiça porem se lhe faça. Nas “Fototipias” Figueiredo Pimentel fingio muito bem que amou, conheceu e examinou praxitelicamente as 28 mulheres, as 28 estatuas de carne, que formam a galeria do livro. [...]”. (A SEMANA, ANO V, n. 38, 21 abr. 1894, p. 299).

Livro mao (1894), livro do gênero lírico de Figueiredo Pimentel com 126 páginas, editado pela Carlos Moraes \& C., foi escrito no período de 1888 a 1894, de acordo com informações constantes na Revista Brazileira. ${ }^{6}$ Segundo Artur Azevedo, subscritor da seção "Palestra”, de O Paiz, edição
${ }^{6}$ A Revista Brazileira foi editada pela Laemmerte \& C. A edição consultada corresponde ao quarto tomo do primeiro ano (1895). 
de 06 de outubro de 1895, a obra tem semelhanças com Flores do mal, do francês Baudelaire, além de que "[o] título é bem achado, porque o livro resumbra mysanthropia e pessimismo em todas as páginas.” (O PAIZ, ANO XII, n. 4022, 06 out. 1895, p. 1).

A edição de 12 de outubro daquele ano do mesmo periódico carioca trouxe, porém, uma crítica desenvolvida em seis parágrafos que caminha no sentido oposto à de Artur Azevedo. Verdade que, apesar de trazer alguns elogios, o crítico não poupou o autor macaense de seu rigor estético: “Debaixo do ponto de vista puramente da arte, o Livro Mao é pessimo, muito embora revele verdadeiros lampejos de talento.” (O PAIZ, ANO XII, n. 4028, 12 out. 1895, p. 2). Mas não se limita ao exposto, pois o subscritor - desconhecido, uma vez que não assina suas colocações - ainda acusa Figueiredo Pimentel de ser descuidado e precipitado e, desembocando no mesmo discurso de apego do autor ao alarde, como o fizeram anteriormente outros homens das letras, afirma que a intenção do escritor era “[...] escandalizar o burguez com umas tantas rebeldias moraes e sociaes já caiu em desuso. (O PAIZ, ANO XII, n. 4028, 12 out. 1895, p. 2).

Valentim Magalhães, na primeira página do número 265, de A notícia, na seção “Semana litteraria”, destacou o pessimismo do livro já desde o título, o qual é confirmado em seu conteúdo: "Intitulou-o Livro mao para prevenir de certo o leitor da perversidade que lhe palpita e babuja nas paginas. E não o engana. O livro é deveras mao como cobra. Lê-se nelle descompostura bravia em Deus, nos homens, no mundo, nas mulheres, e até na própria mãe.” (A NOTICIA, ANO II, n. 265, 16-17 de out. 1895, p. 1).

$\mathrm{O}$ que poderia parecer um elogio nos parece mais um deslouvor à obra, tendo em vista que o crítico deixa claro durante sua exposição que os poemas pecam pela falta de ineditismo: "O livro deixou-me frio inteiramente, por não ser sincero, mas apenas uma imitação exagerada das Blasphemias, de Richepin.” (A NOTÍCIA, ANO II, n. 265, 16-17 de out. 1895, p. 1). Ademais, Valentim Magalhães destaca o apelo ao escândalo já apontado por Artur Azevedo, mas, não obstante as máculas mencionadas, reconhece algum valor artístico do Livro mao: "Sem meia dúzia de peças violentas seria um livro bom. E o que lamento é que o autor o tenha feito mau de proposito. São os gostos...” (A NOTICIA, ANO II, n. 265, 16-17 de out. 1895, p. 1).

No tocante à vendagem, o livro de poemas não causou o mesmo estardalhaço que os romances naturalistas do escritor, mas também não foi negativa a recepção pelo público. Na mesma edição de A noticia, em que fora publicada a crítica de Valentim Magalhães, a qual nos remetemos há pouco, L. B, - também colaborador desse periódico - afirmou que "[a] impressão do Livro mao contrasta com o seu titulo porque é boa e a procura tem sido larga na livraria Fauchon [...]”. (A NOTICIA, ANO II, n. 265, 1617 de out. 1895, p. 3). 
Outra obra lírica de Figueiredo Pimentel foi O amor (1896?). Segundo Valentim Magalhães informa, na seção "Semana litteraria", da edição 37 de A notícia, publicada em 12-13 de fevereiro de 1896, ${ }^{7}$ o livro reúne 43 (quarenta e três) sonetos, cujos versos apresentam-se de forma espontânea, e cujo conjunto é dotado de variedade, harmonia e delicadeza.

Em nota ${ }^{8}$ publicada na edição de $O$ paiz, que circulou em 30 de janeiro de 1896, apresentando a obra como "livro para moças", Amor, embora tivesse a grande preocupação com a estética parnasiana, era rica em delicadeza: "Figueiredo Pimentel tem no Amor estrophes altamente communicativas, sobresaindo, por vezes, imagens formosas que embalam o leitor como se este estivesse na mais deliciosa das suas redes.” (O PAIZ, ANO XII, n. 4137, 30 jan. 1896, p. 4).

Carmen (1897), de Figueiredo Pimentel, editada pela Quaresma \& C., já era anunciada antes de seu lançamento, no Jornal do Brasil, de 6 de dezembro de 1897. A nota descrevia a obra como "[...] um pequenino poema escripto [...].”, e continua dando maiores detalhes: “Do trabalho de impressão sabemos que será um primor typographico, impresso nítida e luxuosamente em papel cetim acartenado, nas conhecidas officinas Leuzinger e Irmãos, da praça Tiradentes. O poemeto Carmen, em tiragem limitada, deve estar prompto por toda a próxima semana.” (JORNAL DO BRASIL, ANO 7, n. 340, 6 dez. 1897, p. 2).

Em nota, a Revista do Brazil, de São Paulo, de março de 1898, trata a obra como "mimoso livrinho", de modo que fora "[...] lido e relido, mesmo decorado.”. E, lamentando a falta de espaço naquela edição, deixou de registrar suas “[...] impressões que são magníficas.” (REVISTA DO BRAZIL, ANO I, n. 9, mar. de 1898, p. 31).

A Gazeta da tarde, de 18 de janeiro de 1898, trouxe uma pequena resenha sobre Carmen tecida por Orlando Teixeira (1874-1902), que se dedica a apresentar a estrutura da obra e a descrição do tema desenvolvido pelo escritor macaense:

[...]

Cinco trabalhos e um post-scriptum que é assim como o resumo de tudo, o verso e o reverso da medalha do amor, do grande amor que transparece em todas as estrofes escriptas "de joelhos, com o fervor de um rente" e inspiradas por uma hespanholita graciosa, creança ainda, pois o poeta nol-a apresenta com quatorize annos e, se bem que nas primeiras estrofes seja dito que ella não nasceu na terra, e veiu das planices azues, nas azas de uma nuvenzinha, no capitulo II o ideal se humanisa um pouco e á gente fica a convicção que Carmen nasceu na Hespanha. [...] No decorrer do livrinho ha versos magníficos, se bem em que alguns trechos se note pouco cuidado, pressa relativa, menos perdoavel ainda em Figueiredo Pimentel que já se fez um nome litterario bastante regular. [...]. (GAZETA DA TARDE, ANO XIX, n. 14, 18 jan. 1898, p. 1)
${ }^{7}$ A NOTICIA, ANO III, n. 37, 12-13 fev. 1896, p. 2.

${ }^{8}$ A referida nota, se comparada com as informações trazidas por Valentim Magalhães publicadas em "Semana litteraria”, de A noticia, levanta uma contradição quanto ao número de sonetos contidos em Amor, de Figueiredo Pimentel. De acordo com a nota de $O$ paiz - que, na verdade, trata-se de reprodução de uma outra idêntica que foi publicada em outro periódico, $A$ cidade do Rio, fato revelado em razão da presença do nome deste jornal entre parênteses no seu desfecho -, o livro tem 59 (cinquenta e nove) sonetos. Em outra nota, agora no periódico fluminense Jornal do commercio (ano LXXV, n. 29, 29 de jan. 1898), fala-se em 53 (cinquenta e três) sonetos. 
O Paiz, de 2-3 de janeiro de 1898, na seção "Kinetoscopio", subscrita por algum colaborador que se identificava apenas com a inicial "R.”, publicou uma crítica de Carmen, em que julga como de qualidade, com versos bem feitos, inclusive, comparando com a estética de Olavo Bilac, Guerra Junqueiro entre outros poetas:

[...] os versos do Figueiredo Pimentel são bem feitos, podendo merecer o "f. s. a." das receitas medicas, tem affirmado todos os entendidos. Accrescentarei apenas que gostei muito da Carmen (é escusado ter ciume, porque refiro-me á poesia e não á mulher.) Os versos são, ao que parece e como resalta das trasncripções, inspirados em outros de Bilac, Guerra Junqueiro, Espronceda, Raymundo Correia e Gonçalves Crespo, mas destinados todos - quadras e tercetos - a cantar a belleza do rosto, a graça e o salero do corpo, o brilho do olhar, a elegância do andar, a musica melodiosa da voz e tudo quanto de bello e de attrahente tem Carmen, a salerosa sevilhana:

Anjo e demônio! As’ vezes doce pranto

chora; e ella, então, émeiga e piedosa,

como um velho prior piedoso e santo.

Outras vezes, porém feroz, raivosa,

Parece o anjo do Mal que o mundo aterra,

N'uma terrivel faina victoriosa,

A semear o Horror, e a Peste e a Guerra...

Talvez por ser vadio, aprecio muito a quem trabalha; e Figueiredo Pimentel, além de trabalhador, é talentoso. Os competentes hão de dar o devido apreço á Carmen, que é o sexto livro de versos desse autor de quatro conhecidos romances e de oito volumes para crianças. Limito-me a dizer que gostei dos versos, porque de nada valeria a opinião de quem, depois dos celebres pipareotes aos 13 annos, nunca mais fez versos na sua vida - nem mesmo iguaes áquelles que certos alemães coantam em Petropolis, á mesa do jantar, no dia do Natal: A xente fique moce/Quando come patata doce./A vida pr'a mim se acabou-se./Quando não como patata doce! (O PAIZ, ANO XIV, n. 4839, 02-03 jan. 1898, p. 1).

Nossa investigação sobre Figueiredo Pimentel, nos periódicos arquivados na Hemeroteca Digital da Biblioteca Nacional, permitiu-nos localizar vestígios de uma produção dramática do autor. Diante dessas informações, recolhemos algumas notas, a fim de ilustrar sua produção no tocante a esse gênero, sem, contudo, exaurir a matéria.

Na seção "Fac et spera”, do número 10, do primeiro ano da Revista do Brazil, de São Paulo, foi publicada uma pequena nota-anúncio sobre Onde está a Felicidade, na qual consta aplausos a Figueiredo Pimentel como
${ }^{9} \mathrm{O}$ PAIZ, ANO XIV, n. 4839, 02-03 jan. 1898, p. 1. 
escritor literário. (REVISTA DO BRAZIL, ANO I, n. 10, abr. 1898, p. 2). Naquele mesmo número da mencionada revista, tivemos a oportunidade de conhecer dois atos do texto dramático Onde está a felicidade, que foi parcialmente publicado (páginas 261 a 264). ${ }^{10}$

Pelo que pudemos inferir, a partir do exemplar a que tivemos acesso, trata-se de uma história cujo enredo é composto por cenas passadas em uma floresta, que quatro jovens, Cresus, Cellini, Platão e Romeu, tentam atravessar, para chegar a um lugar ainda não sabido pelo leitor, e, até o momento, também não conhecido pelos personagens, mas no qual se encontra a felicidade. Durante a jornada pelo caminho que é informado pela Velhinha da floresta, os jovens encontram um peregrino descrito na didascália como um homem bem velhinho, com longuíssimos cabelos e barbas grisalhos, todo vestido de branco. A floresta é uma metáfora usada pelo peregrino dentro do texto, representando, de acordo com que ele apresenta aos jovens, o passado, o presente ou o futuro, e, de acordo com a cor de quem a enxerga, um estado de espírito ou um evento que está sendo vivenciado pelo observador. Embora só tenhamos a oportunidade de ler os dois primeiros atos, pudemos perceber a intenção moralizadora do texto.

Outra nota a que tivemos acesso na Hemeroteca Digital da Biblioteca Nacional trata de um anúncio de estreia do espetáculo teatral Rio s'amuse, que foi publicado na Gazeta de Noticias, do Rio de Janeiro, de 05 de fevereiro de 1909, na seção “Uma opinião pessoal”, assinada por Xinó. De acordo com o colaborador do jornal, a peça fora escrita por Figueiredo Pimentel e Patrocínio Filho, motivo, argumenta o subscritor, pelo qual deve o público prestigiar a peça, “[a]lém disso "Rio s’amuse” tem o encanto inédito de ser franccez. E como se estivessemos em Paris a assistir a scenas ocorridas aqui, entre nós, com typos que conhecemos tão bem, incapazes de "boulevardier" com talento, a dizerem cousas em franzez a [ilegível] em francez!...” (GAZETA DE NOTICIAS, ANO XXXV, n. 36, 05 fev. 1909, p. 3).

\section{Considerações finais}

Este estudo constitui um primeiro passo no caminho de conhecer produções literárias de Figueiredo Pimentel, até então, totalmente ignoradas pela academia. Estigmatizado como provocador de escândalos, em virtude de narrativas contraventoras aos costumes sociais da época, Figueiredo Pimentel alcançou fama, o que abriu espaço para organizar a Biblioteca Infantil da Livraria Quaresma a convite de Pedro Quaresma, na última década do século XIX.

Escrevendo para esse público, teve suas obras esgotadas sempre que eram lançadas, o que provocou reedições em série de vários dos títulos infantis que escreveu. Todavia é um autor pouco conhecido e situado fora da historiografia literária nacional, não compondo o cânone - nem o infantil,
${ }^{10}$ Ao final do texto, no n. 10 da Revista do Brazil, constava a indicação de que seria finalizado no número seguinte, contudo não tivemos acesso a ele, tendo em vista que não está disponível no arquivo da Hemeroteca consultada. 
nem o ordinário. Os estudos que se interessam pela produção literária do autor são raros e não mencionam sua atuação fora da estética naturalista e da literatura infantil. Esperamos que, a partir do que colhemos e informamos neste trabalho, outros pesquisadores se interessem pelo estudo crítico ou mesmo historiográfico sobre o autor e sua contribuição literária para a época, além dos gêneros que ganhou certa visibilidade nos últimos anos, no que diz respeito aos ora tratados.

\section{Referências}

CARVALHO, M. A. R. de. Irineu Marinho: imprensa e cidade. São Paulo: Globo, 2012.

GÓES, F. O carnaval elegante de Figueiredo Pimentel. Textos Escolhidos de Cultura e Arte Populares, v. 12, n. 2, 2015. Disponível em: < http:// www.e-publicacoes.uerj.br/index.php/tecap/article/view/16474>. Acesso em: 19 ago. 2017.

MENDES, L. Apresentação. In: PIMENTEL, F. O aborto. Rio de Janeiro: 7Letras, 2015.

- Livros para Homens: sucessos pornográficos no Brasil no final do século XIX. Cadernos do IL, n. 53, p. 173-191, 2016.

MENDES, L.; LEITE, P. O. As trajetórias de Suicida! (1895) e O terror dos maridos (1896), romances naturalistas esquecidos de Figueiredo Pimentel. Revista Soletras, n. 30, p. 118-138, 2015. Disponível em: <http://www.epublicacoes_teste.uerj.br/index.php/soletras/article/view/19102>. Acesso em: 19 ago. 2017.

NUNES, R. V. Sobre crônicas, cronistas e cidade: Rio de Janeiro nas crônicas de Lima Barreto e Olavo Bilac: 1900-1920. 2009. 194 f. Dissertação (Mestrado em Ciências Humanas) - Instituto de História, Universidade Federal de Uberlândia, Uberlândia, 2009.

SANTOS, H. H. M. dos. Escola normal do Distrito Federal: por trás da modernidade civilizatória da cidade do Rio de Janeiro (1911-1920). Revista Contemporânea de Educação, v. 8, n. 15, 2013, p. 133-153. Disponível em: $\quad<$ https://revistas.ufrj.br/index.php/rce/article/view/1690/1539>. Acesso em: 26 ago. 2017.

SOUZA, J. I. de M. Figueiredo Pimentel e a chegada do cinema ao Rio de Janeiro ou como ser civilizado nos trópicos. Revista USP, n. 54, 2002, p. 136-150. Disponível em: < www.journals.usp.br/revusp/article/ download/35229/37950>. Acesso em: 15 fev. 2018. 
VIEIRA, R. F. Uma penca de canalhas: Figueiredo Pimentel e o naturalismo no Brasil. Dissertação (Mestrado em Letras). Rio de Janeiro: UERJ, 2015.

\section{Fontes Primárias:}

A Noticia. Rio de Janeiro. 1890-1919.

A Semana. Revista Catholica, Litteraria e de Instrucção Publica. Rio de Janeiro. 1885-1895.

Cidade do Rio. Rio de Janeiro. 1887-1902.

Gazeta da Tarde. Rio de Janeiro. 1880-1901.

Gazeta de Noticias. Rio de Janeiro. 1875-1956.

Jornal do Commercio. Rio de Janeiro. 1827-2013.

Jornal do Brasil. Rio de Janeiro. 1890-2018.

O Fluminense. Rio de Janeiro. 1870-2018.

O Paiz. Rio de Janeiro. 1880-1939.

Revista do Brazil. São Paulo. 1880-1909.

Disponíveis em: Hemeroteca Digital da Biblioteca Nacional. <http:// bndigital.bn.gov.br/hemeroteca-digital/> . Acesso em: jan-jul.2018.

Recebido em julho/2018.

Aceito em fevereiro//2019. 